«Системні технологіï» 1 (126) 2020 «System technologies»

DOI 10.34185/1562-9945-1-126-2020-08

УДК 378.14

Н.В. Карпенко, В.В. Герасимов, А.О. Виноградова

\title{
ЗАСТОСУВАННЯ MICROSOFT FORMS У НАВЧАЛЬНОМУ ПРОЦЕСI
}

Анотація. У даній статті показано особливості використання програмного продукту Microsoft Forms для проведення оцінки зрізу знань студентів. За результатами апробації зроблено висновок про доцільність використання даного рішення для тестування у вищих навчальних закладах.

Ключові слова: тестування знань, Microsoft Forms, особистісно-діяльнісний підхід.

Вступ. Одним 3 основних принципів особистісно-діяльнісного підходу до підготовки спеціалістів є забезпечення зв’язку між викладачем і студентом. У процесі навчання студент працює або під керівництвом викладача, або самостійно, причому самостійна робота не виключає викладача повністю, лише зменшується ступінь контролю з його боку. Це передбачає, насамперед, донесення матеріалу та одержання зворотного зв’язку за допомогою сучасної інфраструктури [1]. Автори статті [2] відмічають, що це можливо зробити лише у випадку чітко визначеного порядку використання програмних продуктів для вирішення типових завдань, таких як порядок реєстрації студентів, організація груп, блогів, форумів тощо. Дані правила повинні використовувати всі викладачі, тобто підхід повинен бути єдиним.

Кожен викладач-лектор вищого навчального закладу стикається 3 проблемою визначення прогресу теоретичного навчання окремого студента напротязі семестру. Контрольні та модульні роботи ситуацію повністю не ілюструють, оскільки їх проводять 1-2 рази на семестр і вони показують знання студента в конкретний момент часу. Такий спосіб контролю не є гнучким, оскільки не дозволяє своєчасно виявляти труднощі засвоєння матеріалу. Для більш тісного зворотного зв’язку «викладачстудент» бажано проводити на кожній лекції тестування знань студентів.

Існує досить багато спеціалізованих ПЗ для проведення тестуван-

(C) Карпенко Н.В., Герасимов В.В., Виноградова А.О., 2020 
«Системні технології» 1 (126) 2020 «System technologies»

ня знань, однак основною умовою для вибору ПЗ було його безкоштовне використання, доступність online без обмежень і без встановлення додаткового ПЗ на пристрій, за допомогою якого студент буде проходити тестування. Так, цю задачу можна реалізувати за допомогою веб-додатків для складання тестів Google або Microsoft Forms. Але оскільки нашому навчальному закладу надано ліцензію на використання продукції Microsoft, то метою цієї роботи є висвітлення особливостей роботи саме 3 Microsoft Forms [3], який $€$ частиною потужної сучасної платформи Microsoft Office 365.

Основна частина. Визначимо особливості роботи 3 Microsoft Forms. Для створення тесту потрібно обрати спеціальну форму для тестування, а не для опитування, оскільки тільки ця форма підтримує співставлення одержаних відповідей $з$ правильними.

В таблиці 1 наведено порівняння форм для тесту, які надають Google та Microsoft Forms. Як видно 3 табл. 1, ці засоби мають майже однакові можливості. Так, опцію оцінювання продубльовано в Microsoft Forms шкалою, яка $є$ і в Google Формах, але для контролю знань ця опція не потрібна, так само як і поле для відповіді про зручний час, яке представлено в Google Формах.

Таблиця 1

Порівняння полів для надання відповідей в Google та Microsoft Forms

\begin{tabular}{|c|c|c|c|c|c|c|c|c|c|c|c|c|c|}
\hline & 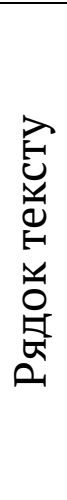 & 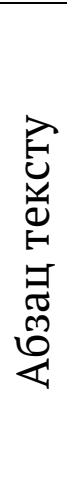 & 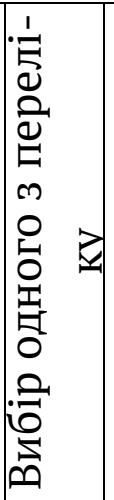 & 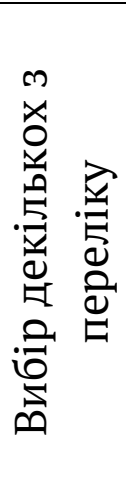 & 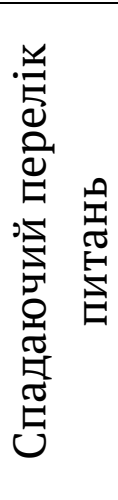 & 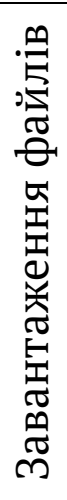 & 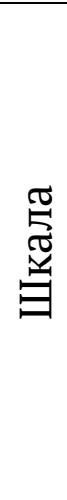 & 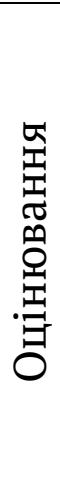 & 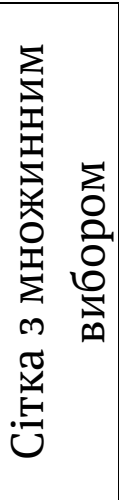 & 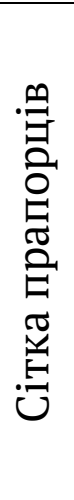 & 崖 & $\stackrel{\sigma}{E}$ & $\underset{\vec{v}}{\vec{v}}$ \\
\hline Google & + & + & + & + & + & + & + & - & + & + & - & + & + \\
\hline Microsoft & + & + & + & + & - & + & + & + & + & - & + & + & - \\
\hline
\end{tabular}


«Системні технологіï» 1 (126) 2020 «System technologies»

На перший погляд створення нового питання зручніше у Google Формах, оскільки це вибір з переліку форм. В Microsoft Forms для вибору форми (з однією або декількома відповідями) та тексту (рядок або абзац) потрібно використовувати додатковий перемикач (рис. 1).

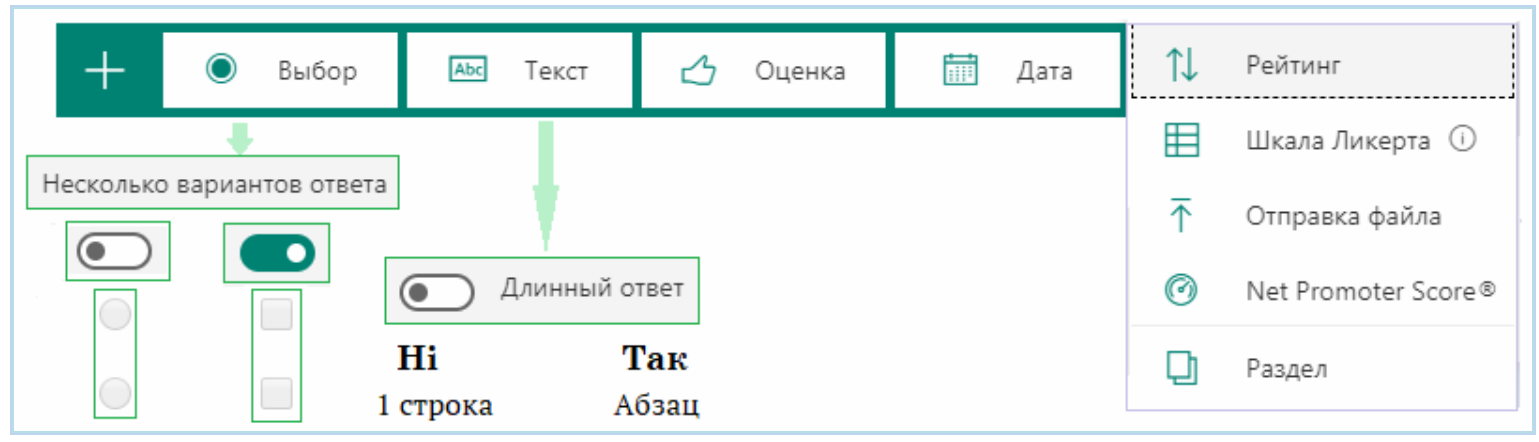

Рисунок 1 - Панель вибору форм для відповіді

Розглянемо особливості полів для надання відповідей. Не дивлячись на автоматизацію процесу тестування, відповіді на деякі питання викладачу потрібно перевіряти вручну. Це питання, відповіді на які представлені текстом, файлом і, як виявилось, Microsoft Forms не надає можливості вписати правильну відповідь у сітку з множинним вибором. I що тоді маємо? У випадку, коли викладач при складанні тесту використовує лише вищевказані поля, то перевірка буде займати такий самий час, як і у випадку, коли студенти пишуть відповіді на аркуші паперу. Тоді такі питання не можна ставити в тести, якщо викладач бажає миттєво одержати результат, оскільки вони не будуть відображені на діаграмі відповідей студентів. 3 іншого боку, студенти зацікавлені одержати результат проходження тесту одразу ж після відправки тесту на перевірку. Це слід враховувати, оскільки у студентів з’являються питання щодо їх помилок.

Для позначення правильних відповідей потрібно питання зробити активним, тоді справа за відповідним полем можна поставити галочку (рис. 2). Одразу ж можна оцінити правильну відповідь певною кількістю балів. Саме питання можна зробити обов’язковим для відповіді. Але у випадку, коли є хоча б одне обов’язкове питання без відповіді, студент не може відправити форму для перевірки до тих пір, поки не позначить 
«Системні технологіï» 1 (126) 2020 «System technologies»

будь-яку відповідь на цьому питанні, що буде вносити корективи в статистику відповідей.

На відміну від Google, Microsoft Forms не тільки надає можливість попереднього перегляду готового тесту чи окремого питання на комп’ютері, але й показує, яким чином його буде відображено на мобільному пристрої.

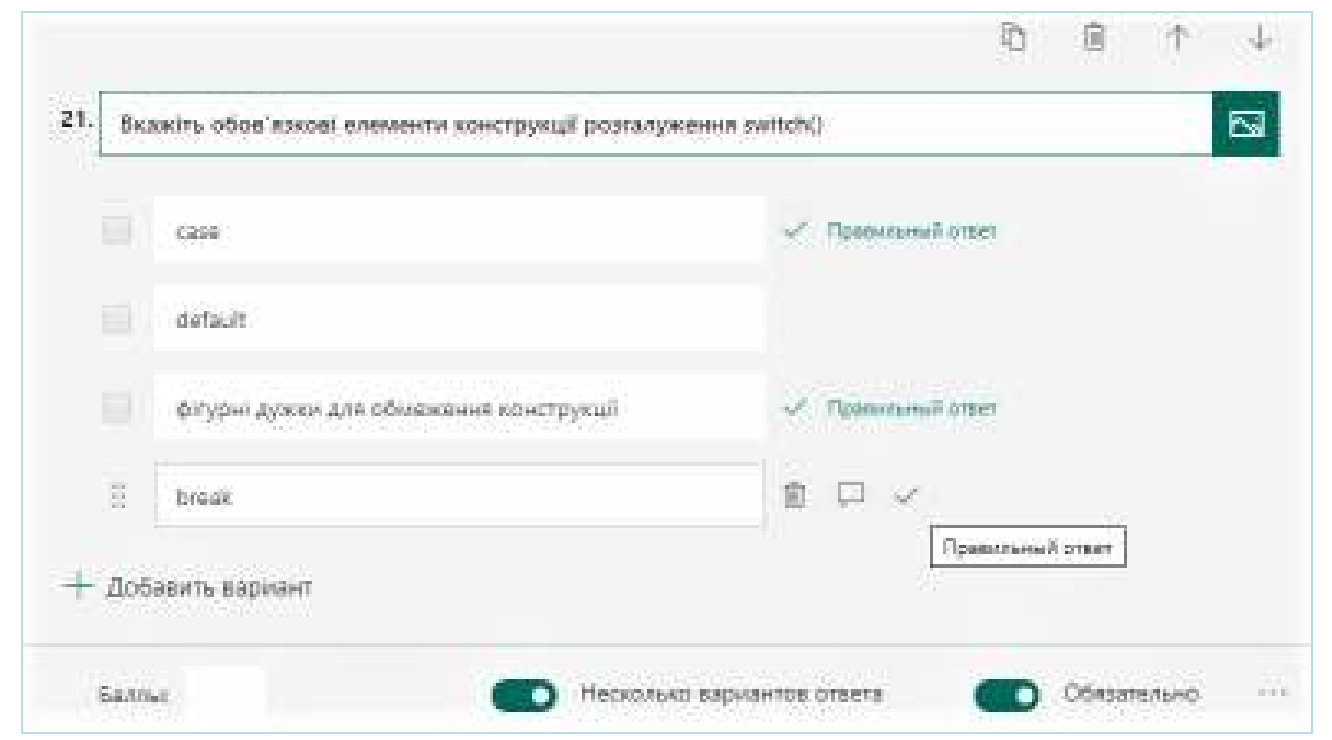

Рисунок 2 - Налаштування тестового питання

Слід відзначити, що питання 3 множинним вибором по-різному буде відображатися на комп’ютері (рис. 3,a) та на телефоні (рис. 3,б).

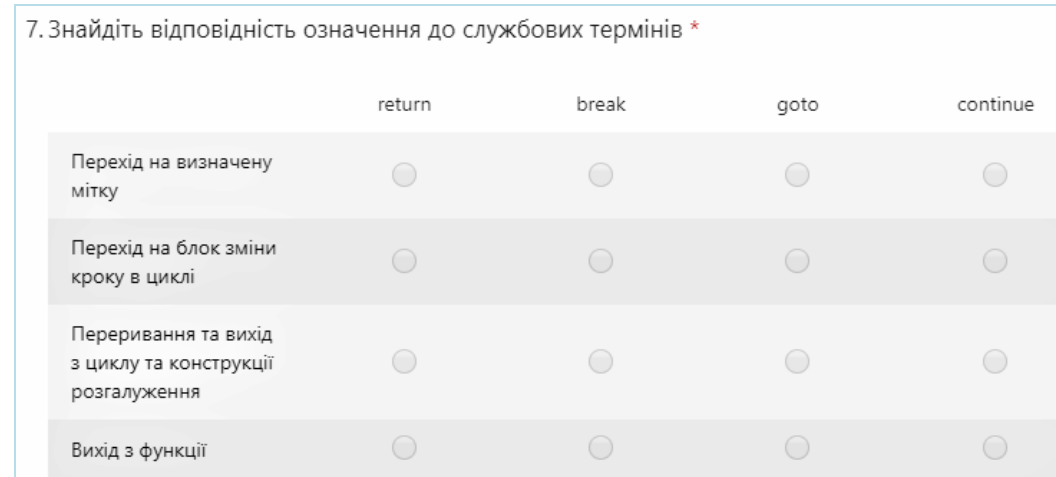

a)

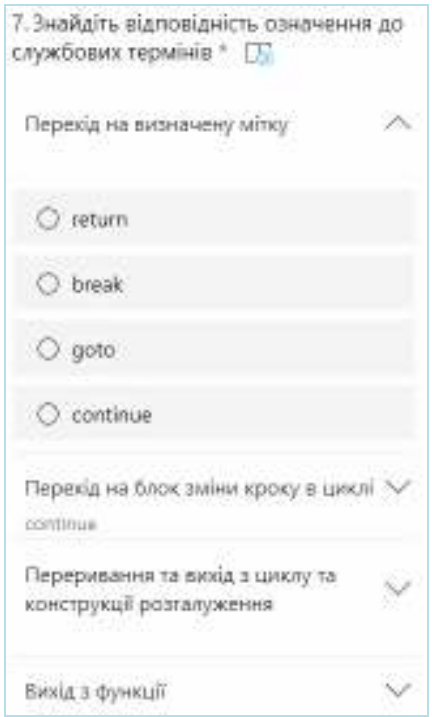

б)

Рисунок 3 - Відображення форми для тестування 3 множинним вибором: а) на комп’ютері; б) на телефоні 
«Системні технології» 1 (126) 2020 «System technologies»

Слід звернути увагу на особливості оцінювання та відображення статистики відповідей. У випадку, коли на питання є тільки одна правильна відповідь (використовується вибір RadioButton), то викладач одразу може побачити розподіл помилкових відповідей і пояснити - де студенти помилилися і чому (рис. 4). I, відповідно, за кожну правильну відповідь студенту нараховуються бали автоматично.

23. Який цикл дозволяє визначити суму чисел з діапазону від 10 до 100?

Правильных ответов на этот вопрос: 40 \% (8 из 20).

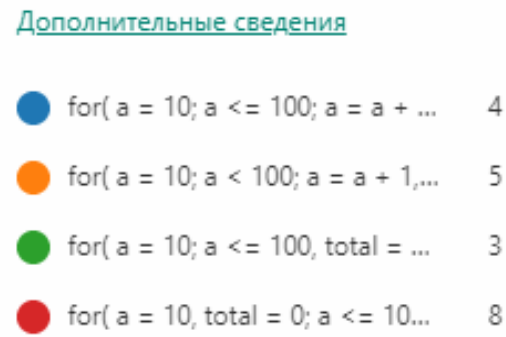

Рисунок 4 - Відображення розподілу відповідей

Коли на питання потрібно обрати 2 або більшу кількість правильних відповідей (використовується вибір CheckBox), то за логікою, закладеною в Microsoft Forms, одна правильна відповідь з декількох не зараховується як правильна, і повинен бути повний комплект відповідей, які позначив викладач галочкою. Так на рис. 5 показано, що тільки 10 \% студентів автоматично одержали бал за відповідь на питання, хоча тільки 2 відповіді є помилковими. Звідси випливає, що автоматично проставлені бали не завжди коректно показують дійсні знання студентів, а лише у випадку, коли вірна тільки одна відповідь. Для питань з декількома правильними відповідями більш коректним $є$ судження, що базується на статистиці (рис. 5,a). 
«Системні технології» 1 (126) 2020 «System technologies»

12. Оберіть правильний варіант для виведення рядка символів char $\operatorname{arr}[100]$ Правильных ответов на этот вопрос: $10 \%$ (2 из 20).

Дополнительные сведения
puts(arr)
gets(arr)
getchar(arr)
putchar(arr)
printf(" $\% s^{n}$, arr $)$
scanf("\%s" arr)

a)

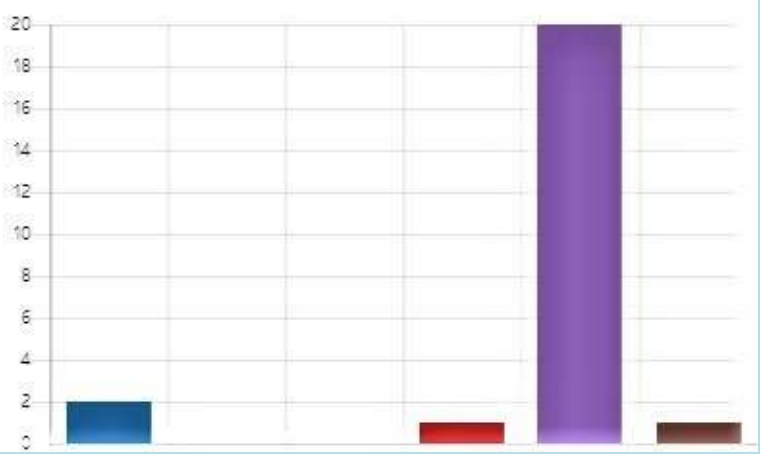

б)

Рисунок 5 - Статистика відповідей:

а) статистика відповідей; б) графічне відображення статистики

Оскільки для Microsoft форми з множинним вибором (рис. 3,a) не можна задати правильні відповіді, то статистики правильних відповідей у даному випадку немає, є лише графічний розподіл відповідей (рис. 6). Як видно з цього рисунку, викладач може лише якісно оцінити знання студентів 3 цього питання. Так, переважна більшість студентів вважає, що переходом на визначену мітку в мові C $є$ оператор goto, а для виходу 3 функції використовується службове слово return тощо.

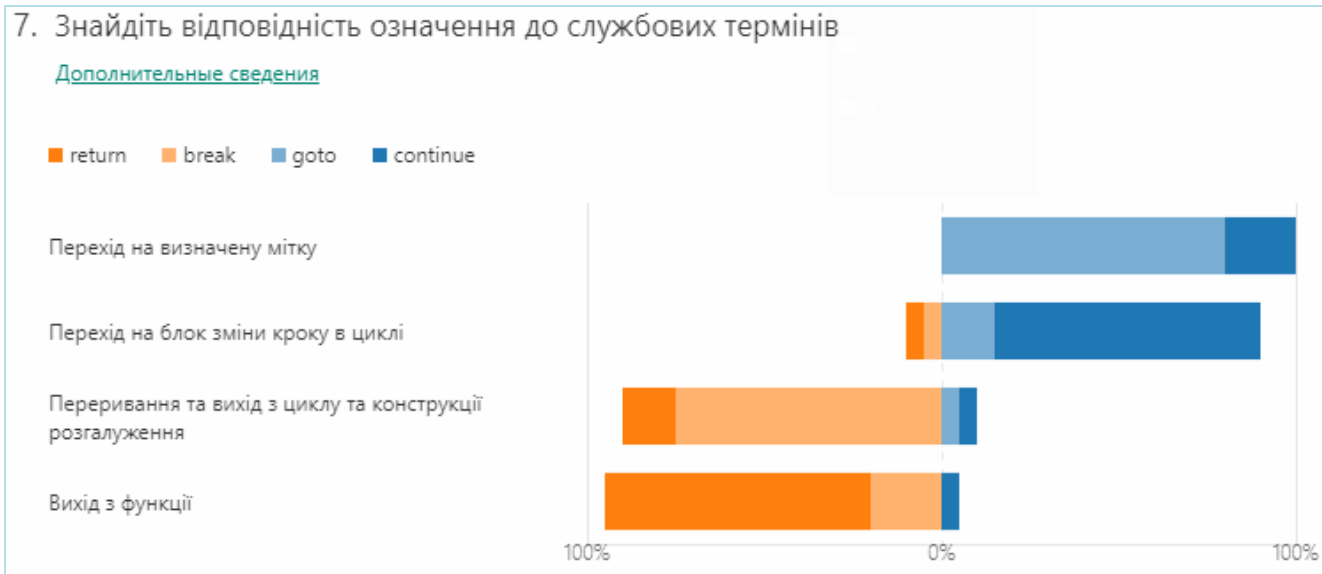

Рисунок 6 - Графік розподілу відповідей для форми з множинним вибором

Окрім графічного та кількісного представлення результатів опитування, існує можливість визначити саме тих студентів, які надали по- 
«Системні технологіï» 1 (126) 2020 «System technologies»

милкову відповідь на питання. Так на рис. 7. показано, що на питання № 18 було надано 20 відповідей, серед яких декілька є помилковими.

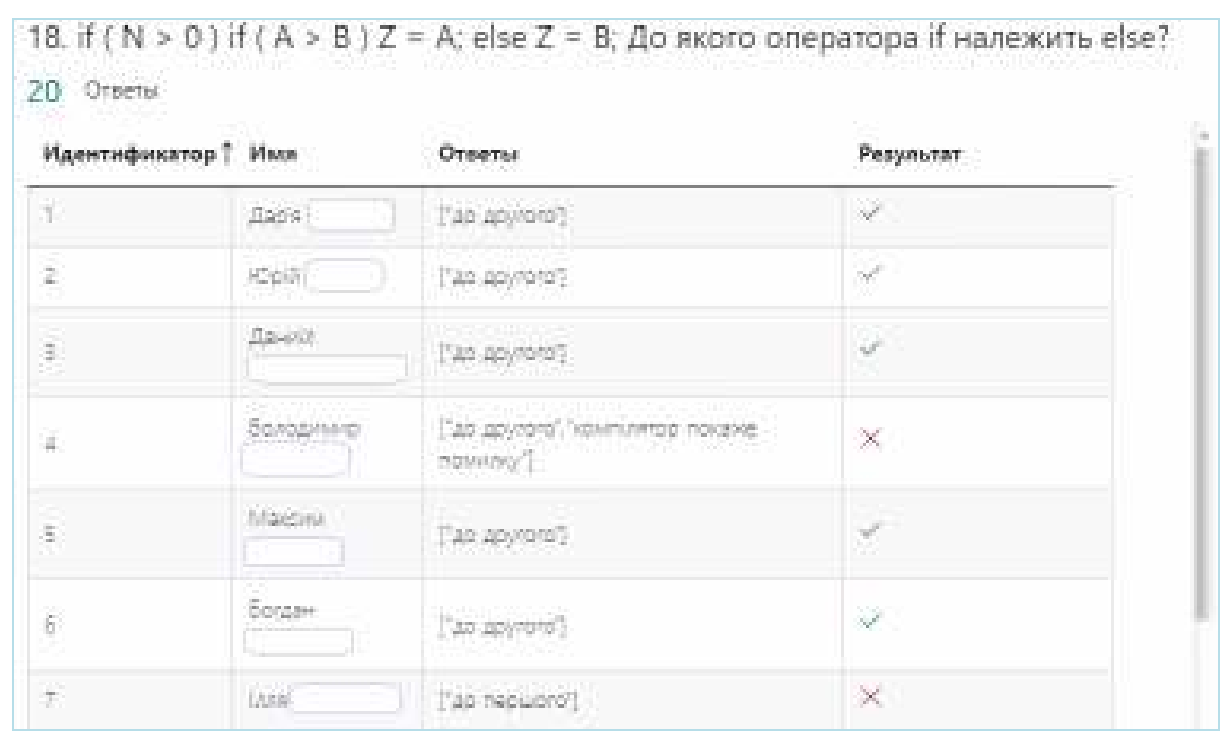

Рисунок 7 - Деталізація відповідей на питання

Для розповсюдження посилання на підготовлений тест можна зробити розсилку на еmail студентів або зробити його у вигляді $\mathrm{QR}$ - коду.

Висновки. Тестування на початку заняття за матеріалом попередньої лекції чи теми покаже, які моменти слід нагадати студентам чи пояснити. I навпаки, тестування, проведене наприкінці лекції, покаже миттєвий зріз того, як студенти зрозуміли саме цю тему. Це дозволить викладачу виявити загальний рівень підготовки студентів до сприйняття нового матеріалу. Окрім того, проаналізувавши результати даного тесту, викладач зможе скорегувати рівень та об'єм нового матеріалу, а також змінити тактику його донесення до слухача.

Для впровадження в навчальний процес та постійного використання Microsoft Forms потрібна відповідна інфраструктура. Найкращим при цьому для викладача є використання комп’ютера, оскільки на ньому легше працювати з декількома потоками даних і зручніше аналізувати різні форми представлення результатів тестування студентів. Для самих студентів достатньо мобільного телефону з доступом до мережі Internet. 
«Системні технології» 1 (126) 2020 «System technologies»

\section{ЛІТЕРАТУРА / ЛИТЕРАТУРА}

1. Литвинов А.А., Карпенко Н.В. Особенности применения личностнодеятельного подхода при подготовке специалистов в области информационных технологий // Системні технології. - 2018. -114 (1) - с. 79-84.

2. Литвинов О.А, Карпенко Н.В. Про впровадження особистіснодіяльнісного підходу до підготовки спеціалістів у галузі інформаційних технологій / О. А. Литвинов, Н. В. Карпенко // Системні технології. - 2019. - 120 (1) - С. 101-106.

3. Документація Microsoft Forms Pro - Microsoft Forms Pro | Microsoft Docs [Електронний ресурс]. Режим доступу: https://docs.microsoft.com/ukua/forms-pro/.

\section{REFERENCES}

1. Litvinov A.A., Karpenko N.V. Peculiarities in applying the personal-active approach to specialists' training in information technologies. // System technology. - 2018. - 114 (1) - P. 79-84.

2. Litvinov A.A., Karpenko N.V. Introduction of personal-active approach to specialists' training in information technologies. // System technology. 2019. - 120(1) - P. 101-106.

Microsoft Forms Pro documentation - Microsoft Forms Pro | Microsoft Docs [Electronic resource]. Access mode: https://docs.microsoft.com/en-us/formspro/.

Received 22.01.2020. Accepted 24.01.2020.

\section{Применение Microsoft Forms в учебном процессе}

В данной статье показаны особенности программного продукта Microsoft Forms для оценивания уровня знаний студентов. По результатам апробации сделан вывод про целесообразность использования данного решения для проверки теоретических и практических знаний студентов в высших учебных заведениях.

\section{Application of Microsoft Forms in teaching and learning activities}

This paper shows the features of using the Microsoft Forms for assessing knowledge in students. Based on the results of testing, it was concluded that it is advisable to apply this solution for testing in higher educational institutions.

Testing at the beginning of the class on the material of the previous lecture or topic will show which points should be reminded to students or explained. Conversely, testing conducted at the end of the lecture will show an instant assessment of how students understood this topic. This will allow the teacher to identify the general level of students' preparation for the perception of new material. In addition, having analyzed the results of this assessment, the teacher will be able to adjust the level and volume of the new material, as well as to change the tactics of delivering it to the listener. 
«Системні технологіï» 1 (126) 2020 «System technologies»

For implementation in the teaching and learning activities and the use of Microsoft Forms on a regular basis, it is necessary to have the appropriate infrastructure. In this case, the best for the teacher is the use of a computer, since it is easier to work with several data streams on it and it is more convenient to analyze various forms of presenting student test results. For the students themselves, a smartphone with access to the Internet is enough.

Карпенко Надежда Валерьевна - к.ф.-м.н, доцент кафедры электронных вычислительных машин Днепровского национального университета имени Олеся Гончара.

Герасимов Владимир Владимирович - доцент кафедры электронных вычислительных машин Днепровского национального университета имени Олеся Гончара.

Виноградова Анастасия Александровна - студентка гр. КИ-16-1 кафедры ЭВМ Днепровского национального университета имени Олеся Гончара.

Карпенко Надія Валеріївна - к.ф.-м.н, доцент кафедри електронних обчислювальних машин Дніпровського національного університету імені Олеся Гончара.

Герасимов Володимир Володимирович - доцент кафедри електронних обчислювальних машин Дніпровського національного університету імені Олеся Гончара.

Виноградова Анастасія Олександрівна - студентка гр. KI-16-1 кафедри ЕОМ Дніпровського національного університету імені Олеся Гончара.

Karpenko Nadija - Associate Professor of Computer Systems Engineering Department of Oles Honchar Dnipro National University.

Gerasimov Vladimir - Associate Professor of Computer Systems Engineering Department of Oles Honchar Dnipro National University.

Vinogradova Anastasia - student gr. KI-16-1, Computer Engineering Department, Oles Honchar Dnipro National University. 